\title{
Sequências de lisina digestível para suínos de duas linhagens selecionadas para alta deposição de carne
}

\author{
Sequences of digestible lysine for barrows of two lines selected for meat deposition
}

\author{
FORTES, Eduardo Ianino ${ }^{1}$; DONZELE, Juarez Lopes ${ }^{1}$; OLIVEIRA, Rita Flávia \\ Miranda $^{1}$; SARAIVA, Alysson ${ }^{1 *}$; SILVA, Francisco Carlos de Oliveira ${ }^{2}$; SOUZA, \\ Matheus Faria ${ }^{1}$
}

\author{
${ }^{1}$ Universidade Federal de Viçosa, Centro de Ciências Agrárias, Departamento de Zootecnia, Viçosa, \\ Minas Gerais, Brasil. \\ ${ }^{2}$ Empresa de Pesquisa Agropecuária de Minas Gerais, Viçosa, Minas Gerais, Brasil. \\ *Endereço para correspondência: alysson_zoo@yahoo.com.br
}

\section{RESUMO}

Foi conduzido um experimento para avaliar sequências de lisina digestível sobre o desempenho e características de carcaça de suínos machos castrados. Foram utilizados 96 animais de duas linhagens selecionadas para deposição de carne, com peso inicial de 23,80 \pm $1,07 \mathrm{~kg}$. Os suínos foram distribuídos em um delineamento experimental de blocos ao acaso, em um esquema fatorial $4 \times 1 \times 2$ (quatro sequências de lisina digestível e duas linhagens), com seis repetições e dois animais por unidade experimental. Os tratamentos corresponderam às seguintes sequências de lisina digestível: $\mathrm{S} 1=0,80-0,70-0,60 \% ; \mathrm{S} 2=$ $0,90-0,80-0,70 \%$; S3 $=1,00-0,90-0,80 \%$ e $\mathrm{S} 4=1,10-1,00-0,90 \%$, fornecidos respectivamente nas fases de 63 a $103 ; 104$ a 133 e de 134 a 163 dias de idade. Não houve interação entre as sequências de lisina e linhagem. Os tratamentos não influenciaram o desempenho (ganho de peso diário, consumo de ração diário e conversão alimentar) e as características de carcaça (espessura de toucinho e quantidade de carne). O consumo diário de lisina digestível aumentou de forma linear com o aumento dos níveis de lisina digestível. A sequência de lisina digestível S1 $(0,80 ; 0,70$ e $0,60 \%$ ) atende as exigências para desempenho e características de carcaça.

Palavras chave: aminoácido, carcaça, desempenho, genótipo

\section{SUMMARY}

One experiment was conducted to evaluate sequences of digestible lysine on the performance and carcass traits of castrated male pigs. Ninety six barrows from two lines selected for meat deposition with initial weight of $23.78 \pm 1.07 \mathrm{~kg}$ were used. The animals were allotted in a completely randomized block design, with a 4 × 2 factorial scheme (four digestible lysine sequences and two lines of pigs), with six replicates and two pigs per experimental unit that was represented by the pen. Treatments corresponded to the following sequences of digestible lysine levels: $\mathrm{S} 1=0.80$ $-0.70-0.60 \%$; S2 $=0.90-0.80-0.70 \%$; S3 $=$ $1.00-0.90-0.80 \%$, and S4 $=1.10-1.00-$ $0.90 \%$ provided in the phases of 63 to 103,104 to 133 , and 134 to 163 days old, respectively. There was no interaction between the sequences of lysine and the lines of pigs for any variable of performance and carcass traits assessed. The sequences of digestible lysine did not influence performance parameters (average daily gain, average feed intake, and feed conversion) and carcass traits (backfat thickness, meat amount). The daily lysine intake increased linearly by increasing digestible lysine levels. The sequence of digestible lysine S1 $(0.80 ; 0.70$, and $0.60 \%)$ meets pig's requirement of both lines of pigs for performance and carcass traits.

Keywords: amino acid, carcass, genotype, performance 


\section{INTRODUÇ̃̃O}

A deposição de proteína corporal é determinada pelo genótipo dos suínos e somente ocorrerá de forma eficiente quando os nutrientes forem fornecidos o mais próximo possível da exigência dos animais. Assim, a formulação de rações requer informações precisas das exigências desses nutrientes, entre eles os aminoácidos, nas diversas fases da criação, para permitir a máxima expressão do potencial produtivo dos animais.

As linhagens atuais de suínos apresentam elevado potencial para deposição de carne, característica com maior influência sobre as exigências de aminoácidos, principalmente a de lisina digestível. A lisina é um nutriente diretamente relacionado com o crescimento muscular, assim, as respostas de desempenho e de deposição de carne dos suínos podem estar associadas ao nível de lisina digestível da ração (YEN et al., 1986; OLIVEIRA et al., 2003a).

A seleção de suínos para deposição de tecido muscular tem resultado no aumento da exigência de lisina digestível (ABREU et al., 2007ab), dessa forma, é necessária a constante revisão, por meio de estudos de desempenho, das exigências das atuais linhagens de suínos.

As linhagens modernas disponíveis no mercado apresentam ritmos elevados de crescimento e altas taxas de deposição muscular. Mas, existem variações no potencial de crescimento e na eficiência de conversão do alimento em ganho de peso entre animais de diferentes grupos genéticos, o que pode resultar em exigências de lisina digestível diferenciadas. Portanto, a avaliação por meio de planos de nutrição das exigências de lisina digestível de suínos com diferentes potenciais genéticos torna-se necessária.

Este estudo foi realizado para determinar o melhor plano nutricional, baseado em níveis de lisina digestível, para suínos machos castrados de duas linhagens, selecionados para deposição de carne, nas fases de crescimento e terminação (63 aos 163 dias de idade).

\section{MATERIAL E MÉTODOS}

O experimento foi conduzido no Setor de Suinocultura do Departamento de Zootecnia da Universidade Federal de Viçosa (UFV), Viçosa, MG.

Foram utilizados 96 suínos machos castrados (48 da linhagem denominada A e 48 da linhagem denominada B), híbridos comerciais, com peso médio de $23,80 \pm 1,07 \mathrm{~kg}$, distribuídos em um delineamento experimental de blocos ao acaso, em esquema fatorial $4 \times 2$ (quatro sequências de lisina digestível e duas linhagens), com seis repetições e dois animais por unidade experimental. $\mathrm{O}$ peso inicial e o grupo genético foram considerados como critérios na formação dos blocos.

Os animais foram alojados em baias dotadas de comedouros semiautomáticos e bebedouros tipo chupeta, localizadas em prédio de alvenaria, com piso de concreto e coberto com telhas de cerâmica.

Cada sequências de lisina digestível (Tabela 1) foi dividido em três fases: dos 63 a 103; dos 104 aos 133 e dos 134 aos 163 dias de idade.

As rações experimentais (Tabela 2, 3 e 4) foram formuladas para atender às exigências nutricionais dos animais em cada fase, de acordo com Rostagno et al. (2005), exceto para lisina digestível. Foi mantida a relação ideal de aminoácidos conforme recomendação preconizada por Rostagno et al. (2005). 
Rev. Bras. Saúde Prod. Anim., Salvador, v.13, n.2, p.480-490 abr./jun., 2012 http://www.rbspa.ufba.br ISSN 15199940

Tabela 1. Sequências de lisina digestível de acordo com a idade dos animais

\begin{tabular}{lccc}
\hline & \multicolumn{3}{c}{ Fase (dias) } \\
\cline { 2 - 4 } Sequência & $63-103$ & $104-133$ & $134-163$ \\
\cline { 2 - 4 } & 0,80 & Nível de lisina digestível (\%) \\
\hline 1 & 0,90 & 0,70 & 0,60 \\
2 & 1,00 & 0,80 & 0,70 \\
3 & 1,10 & 0,90 & 0,80 \\
4 & & 1,00 & 0,90 \\
\hline
\end{tabular}

Tabela 2. Composições percentuais e calculadas das dietas experimentais (63 aos 103 dias de idade)

\begin{tabular}{lcccc}
\hline & \multicolumn{4}{c}{ Níveis de lisina digestível (\%) } \\
\cline { 2 - 5 } Ingrediente & 0,80 & 0,90 & 1,00 & 1,10 \\
\hline Milho & 67,300 & 67,300 & 67,300 & 67,300 \\
Farelo de soja & 26,600 & 26,600 & 26,600 & 26,600 \\
Núcleo de recria $^{1}$ & 4,000 & 4,000 & 4,000 & 4,000 \\
Óleos de soja $_{\text {Amido }}$ & 0,870 & 0,870 & 0,870 & 0,870 \\
Promotor de crescimento & 1,170 & 0,948 & 0,678 & 0,333 \\
BHT & 0,050 & 0,050 & 0,050 & 0,050 \\
L-lisina HCl & 0,010 & 0,010 & 0,010 & 0,010 \\
DL-metionina & 0,000 & 0,129 & 0,259 & 0,387 \\
L-treonina & 0,000 & 0,025 & 0,088 & 0,150 \\
L-triptofano & 0,000 & 0,008 & 0,081 & 0,153 \\
L-valina & 0,000 & 0,000 & 0,004 & 0,023 \\
Total & 0,000 & 0,000 & 0,000 & 0,024 \\
\hline Composição nutricional calculada & 100,00 & 100,00 & 100,00 & 100,00 \\
\hline Proteína bruta (\%) & 17,680 & 17,830 & 18,040 & 18,270 \\
Energia metabolizável (kcal/kg) & 3200 & 3200 & 3200 & 3200 \\
Lisina digestível (\%) & 0,800 & 0,900 & 1,000 & 1,100 \\
Triptofano digestível & 0,187 & 0,187 & 0,191 & 0,210 \\
Treonina digestível (\%) & 0,587 & 0,595 & 0,661 & 0,726 \\
Metionina + cistina digestível (\%) & 0,524 & 0,549 & 0,610 & 0,671 \\
Isoleucina digetível (\%) & 0,668 & 0,668 & 0,668 & 0,668 \\
Valina digestível (\%) & 0,746 & 0,746 & 0,746 & 0,770 \\
Cálcio (\%) & 0,665 & 0,665 & 0,665 & 0,665 \\
Fósforo disponível (\%) & 0,340 & 0,340 & 0,340 & 0,340 \\
\hline
\end{tabular}

${ }^{1}$ Fornecendo por quilograma: 93.000 UI vitamina $A, 24.000$ UI vitamina $\mathrm{D}_{3}, 106 \mathrm{mg}$ vitamina $\mathrm{E}, 53 \mathrm{mg}$ vitamina $\mathrm{K}_{3}, 13,3 \mathrm{mg}$ Tiamina, $173 \mathrm{mg}$ Ácido Pantotênico, 0,42mg Biotina, 13,3mg Piridoxina - Vitamina $\mathrm{B}_{6} \mathrm{HCl}, 8,8 \mathrm{mg}$ ácido fólico, 520mcg vitamina $\mathrm{B}_{12,} 112 \mathrm{~g}$ Cálcio (mín.), 27,0g Fósforo (mín.), 58,5g Sódio, $1.820 \mathrm{mg}$ Ferro, $2.049 \mathrm{mg}$ zinco, $2.126 \mathrm{mg}$ cobre, $836 \mathrm{mg}$ Manganês, $29,5 \mathrm{mg}$ Iodo, $485 \mathrm{mg}$ Flúor (máx.), $8 \mathrm{mg}$ Selênio, $3,6 \mathrm{mg}$ Cobalto. 
Tabela 3. Composições percentuais e calculadas das dietas experimentais (104 aos 133 dias de idade)

\begin{tabular}{|c|c|c|c|c|}
\hline \multirow{2}{*}{ Ingrediente } & \multicolumn{4}{|c|}{ Níveis de lisina digestível (\%) } \\
\hline & 0,70 & 0,80 & 0,90 & 1,00 \\
\hline Milho & 72,600 & 72,600 & 72,600 & 72,600 \\
\hline Farelo de soja & 22,300 & 22,300 & 22,300 & 22,300 \\
\hline Núcleo de recria & 4,000 & 4,000 & 4,000 & 4,000 \\
\hline Amido & 1,100 & 0,943 & 0,665 & 0,288 \\
\hline L-lisina $\mathrm{HCl}$ & 0,000 & 0,128 & 0,256 & 0,390 \\
\hline DL-metionina & 0,000 & 0,014 & 0,078 & 0,142 \\
\hline L-treonina & 0,000 & 0,012 & 0,086 & 0,161 \\
\hline L-isoleucina & 0,000 & 0,000 & 0,000 & 0,066 \\
\hline L-triptofano & 0,000 & 0,003 & 0,015 & 0,035 \\
\hline L-valina & 0,000 & 0,000 & 0,000 & 0,018 \\
\hline Total & 100,00 & 100,00 & 100,00 & 100,00 \\
\hline \multicolumn{5}{|l|}{ Composição nutricional calculada } \\
\hline Proteína bruta $(\%)$ & 16,160 & 16,300 & 16,520 & 16,760 \\
\hline Energia metabolizável (kcal/kg) & 3167 & 16,300 & 16,520 & 16,760 \\
\hline Lisina digestível $(\%)$ & 0,700 & 0,800 & 0,900 & 1,000 \\
\hline Triptofano digestível & 0,166 & 0,169 & 0,180 & 0,200 \\
\hline Treonina digestível (\%) & 0,534 & 0,545 & 0,612 & 0,680 \\
\hline Metionina + cistina digestível $(\%)$ & 0,490 & 0,505 & 0,567 & 0,630 \\
\hline Isoleucina digetível (\%) & 0,601 & 0,601 & 0,601 & 0,669 \\
\hline Valina digestível (\%) & 0,682 & 0,682 & 0,682 & 0,700 \\
\hline Cálcio $(\%)$ & 0,644 & 0,644 & 0,644 & 0,644 \\
\hline Fósforo disponível (\%) & 0,335 & 0,335 & 0,335 & 0,335 \\
\hline
\end{tabular}

${ }^{1}$ Fornecendo por quilograma: 93.000 UI vitamina A, 24.000 UI vitamina $\mathrm{D}_{3}, 106 \mathrm{mg}$ vitamina E, 53mg vitamina $\mathrm{K}_{3}$, 13,3mg Tiamina, $173 \mathrm{mg}$ Ácido Pantotênico, 0,42mg Biotina, 13,3mg Piridoxina - Vitamina $\mathrm{B}_{6} \mathrm{HCl}, 8,8 \mathrm{mg}$ ácido fólico, 520mcg vitamina $\mathrm{B}_{12}$, 112g Cálcio (mín.), 27,0g Fósforo (mín.), 58,5g Sódio, 1.820mg Ferro, 2.049mg zinco, 2.126mg cobre, 836mg Manganês, 29,5mg Iodo, 485mg Flúor (máx.), 8mg Selênio, 3,6mg Cobalto. 
Tabela 4. Composições percentuais e calculadas das dietas experimentais (134 aos 163 dias de idade)

\begin{tabular}{|c|c|c|c|c|}
\hline \multirow{2}{*}{ Ingrediente } & \multicolumn{4}{|c|}{ Níveis de lisina digestível (\%) } \\
\hline & 0,60 & 0,70 & 0,80 & 0,90 \\
\hline Milho & 76,800 & 76,800 & 76,800 & 76,800 \\
\hline Farelo de soja & 18,100 & 18,100 & 18,100 & 18,100 \\
\hline Núcleo de recria & 4,000 & 4,000 & 4,000 & 4,000 \\
\hline Amido & 1,100 & 0,975 & 0,710 & 0,407 \\
\hline L-lisina $\mathrm{HCl}$ & 0,000 & 0,125 & 0,254 & 0,383 \\
\hline DL-metionina & 0,000 & 0,000 & 0,050 & 0,114 \\
\hline L-treonina & 0,000 & 0,000 & 0,071 & 0,146 \\
\hline L-triptofano & 0,000 & 0,000 & 0,015 & 0,035 \\
\hline L-valina & 0,000 & 0,000 & 0,000 & 0,015 \\
\hline Total & 100,00 & 100,00 & 100,00 & 100,00 \\
\hline \multicolumn{5}{|l|}{ Composição nutricional calculada } \\
\hline Proteína bruta $(\%)$ & 3,175 & 3,175 & 3,175 & 3,175 \\
\hline Energia metabolizável (kgcal/kg) & 14,600 & 14,600 & 14,600 & 14,600 \\
\hline Lisina digestível $(\%)$ & 0,600 & 0,700 & 0,800 & 0,900 \\
\hline Triptofano digestível & 0,145 & 0,145 & 0,161 & 0,181 \\
\hline Treonina digestível $(\%)$ & 0,480 & 0,480 & 0,551 & 0,626 \\
\hline Metionina + cistina digestível $(\%)$ & 0,456 & 0,456 & 0,506 & 0,570 \\
\hline Isoleucina digetível (\%) & 0,532 & 0,532 & 0,532 & 0,532 \\
\hline Valina digestível (\%) & 0,616 & 0,616 & 0,616 & 0,631 \\
\hline Cálcio (\%) & 0,633 & 0,633 & 0,633 & 0,633 \\
\hline Fósforo disponível (\%) & 0,330 & 0,330 & 0,330 & 0,330 \\
\hline
\end{tabular}

TFornecendo por quilograma: 93.000 UI vitamina $\mathrm{A}, 24.000$ UI vitamina $\mathrm{D}_{3}$, 106mg vitamina E, 53mg vitamina $\mathrm{K}_{3}, 13,3 \mathrm{mg}$ Tiamina, 173mg Ácido Pantotênico, 0,42mg Biotina, 13,3mg Piridoxina - Vitamina $\mathrm{B}_{6} \mathrm{HCl}, 8,8 \mathrm{mg}$ ácido fólico, 520mcg vitamina $\mathrm{B}_{12}$, 112g Cálcio (mín.), 27,0g Fósforo (mín.), 58,5g Sódio, 1.820mg Ferro, 2.049mg zinco, 2.126mg cobre, 836mg Manganês, 29,5mg Iodo, 485mg Flúor (máx.), 8mg Selênio, 3,6mg Cobalto. 
As rações e a água foram fornecidas à vontade durante todo $o$ período experimental que teve duração de 100 dias, cujo início foi aos 63 dias e o término aos 163 dias de idade dos animais. As rações, as sobras e os desperdícios foram pesados periodicamente e os animais pesados no início e no final do período experimental para determinação do consumo de ração médio diário, do ganho de peso médio diário e da conversão alimentar.

No final do período experimental, os suínos foram submetidos ao jejum alimentar de 12 horas e então encaminhados para o abate, realizado no Frigorífico Industrial Vale do Piranga (FRIVAP). Os animais foram previamente insensibilizados por eletronarcose, conforme as normas de bem estar animal e, posteriormente, as carcaças foram limpas e evisceradas. As carcaças passaram por avaliação de rendimento de carne e espessura de toucinho $\left(\mathrm{EPT}_{2}\right)$, por meio de aparelho de tipificação de carcaça (GP-4 Henessy - Nova Zelândia - Solft Didai).

A baia foi considerada a unidade experimental para análise das variáveis de desempenho (consumo de ração médio diário, ganho de peso médio diário e conversão alimentar) e de carcaça (área de olho de lombo, espessura de toucinho e quantidade de carne), de acordo com o seguinte modelo estatístico:

$Y_{\mathrm{ijk}}=\mu+\tau_{\mathrm{i}}+\beta_{\mathrm{j}}+(\tau \beta)_{\mathrm{ij}}+\epsilon_{\mathrm{ijk}}$

Em que: $Y_{\mathrm{ijk}}=$ característica observada; $\mu=$ média geral do tratamento; $\tau_{\mathrm{i}}=$ efeito dos níveis de lisina $\mathrm{i}, \mathrm{i}=1,2 \ldots \mathrm{e}$ $4 ; \beta_{\mathrm{j}}=$ efeito da linhagem $\mathrm{j} ; \mathrm{j}=1$ e 2 ; $(\tau \beta)_{\mathrm{ij}}=$ efeito da interação dos níveis de lisina digestível e linhagem; $\mathrm{e}_{\mathrm{ijk}}=$ erro aleatório associado a cada observação.

\section{RESULTADOS E DISCUSSÃO}

Não houve interação $(\mathrm{P}>0,05)$ entre as sequências de lisina digestível e as linhagens em relação às variáveis de desempenho e de características de carcaça. Não houve efeito $(\mathrm{P}>0,05)$ dos níveis de lisina digestível dentro das fases para nehuma das variáveis avaliadas.

Independente da linhagem, as sequências de lisina digestível não influenciaram $(\mathrm{P}>0,05)$ o ganho de peso médio diário (GPD) dos suínos (Tabela 5). Esse resultado está coerente com os obtidos por Gomes et al. (2000), Oliveira et al. (2003b) e Kill et al. (2003) que também não constataram influência sequências de lisina digestível, sobre o ganho de peso médio diário de suínos dos 80 aos 100 , dos 95 aos 125 e dos 65 aos $105 \mathrm{~kg}$, respectivamente. De forma semelhante, em estudo anterior, Owen et al. (1994) avaliaram a exigência de lisina dos suínos dos 22 aos $109 \mathrm{~kg}$, e constataram efeito dos níveis de lisina sobre o ganho de peso médio diário dos animais somente dos 78 aos $109 \mathrm{~kg}$, onde o nível de lisina total $(0,62 \%)$, que proporcionou a melhor resposta para essa variável, ficou abaixo do menor nível de lisina digestível avaliado neste estudo. Da mesma forma, Hahn et al. (1995) não verificaram melhora no ganho de peso médio diário de suínos machos castrados com níveis de lisina superiores a 0,58 e $0,49 \%$ para as fases de 50 a 90 e 90 a $110 \mathrm{~kg}$, respectivamente.

Em contrapartida, Arouca et al. (2004 e 2007), ao trabalharem com suínos machos castrados na fase de terminação tardia (95 a $122 \mathrm{~kg})$, observaram que os níveis de lisina influenciaram positivamente o ganho de peso médio diário dos animais. 
Rev. Bras. Saúde Prod. Anim., Salvador, v.13, n.2, p.480-490 abr./jun., 2012 http://www.rbspa.ufba.br ISSN 15199940

Tabela 5. Desempenho e característica de carcaça de suínos machos castrados de duas linhagens em função de diferentes sequências de lisina digestível dos 63 aos 163 dias de idade

\begin{tabular}{lccccccc}
\hline & \multicolumn{4}{c}{ Plano } & \multicolumn{2}{c}{ Genética } & CV \\
\cline { 2 - 7 } Variáveis & 1 & 2 & 3 & 4 & A & B & (\%) \\
\hline Peso médio inicial $(\mathrm{kg})$ & 24,05 & 23,70 & 23,90 & 23,50 & 23,70 & 23,80 & 2,67 \\
Peso médio final $(\mathrm{kg})$ & 128,60 & 125,80 & 124,30 & 126,10 & 127,70 & 124,70 & 4,58 \\
Ganho de peso (g/dia) & 1.046 & 1.022 & 1.004 & 1.025 & 1.039 & 1008 & 5,56 \\
Consumo ração (g/dia) & 2.917 & 2.813 & 2.756 & 2.875 & 2.860 & 2.816 & 5,25 \\
Conversão alimentar & 2,79 & 2,75 & 2,75 & 2,81 & 2,75 & 2,79 & 3,49 \\
CLD (g/dia) & $17,50^{\mathrm{a}}$ & $19,70^{\mathrm{b}}$ & $22,05^{\mathrm{c}}$ & $25,90^{\mathrm{d}}$ & 21,5 & 21,1 & 6,56 \\
ET (mm) & 17,70 & 19,05 & 18,80 & 17,10 & 18,90 & 17,50 & 13,53 \\
QC $(\mathrm{kg})^{3}$ & 49,10 & 47,90 & 50,20 & 49,00 & 48,60 & 49,50 & 5,41 \\
\hline
\end{tabular}

Médias seguidas por letras diferentes na mesma linha diferem entre si pelo teste de Tukey a $5 \%$ de probabilidade.

${ }^{1}$ Consumo de lisina digestível; ${ }^{2}$ Espessura de toucinho; ${ }^{3}$ Quantidade de carne na carcaça.

A exigência nutricional dos suínos, entre elas a de aminoácidos digestíveis, pode ser afetada por fatores como sexo, temperatura ambiental e nível de desafio imune, aos quais os animais são submetidos (LEFLOC'H et al., 2004; LEFLOC'H et al., 2008, TREVISI et al., 2009). Em conjunto com esses fatores, a divergência de resultados observada entre os trabalhos, quanto à influência dos níveis de lisina digestível sobre o ganho de peso médio diário dos suínos pode estar relacionada ao potencial genético dos animais para deposição muscular. Essa inferência tem sustentação nos relatos de Yen et al. (1986) de que as respostas de desempenho e de deposição de carne podem ser associadas ao nível de lisina da ração, devido a exigência em maior quantidade desse aminoácido para deposição protéica, e em razão de sua elevada concentração nos tecidos musculares dos suínos.

Essas afirmativas são corroboradas, em estudos conduzidos para avaliar a exigência de lisina digestível de suínos machos castrados de dois grupos com diferentes potenciais genéticos, nas fases de crescimento e terminação, nos quais Gasparotto et al. (2001) e Moreira et al. (2002) constataram que o efeito do nível de lisina sobre o ganho de peso médio diário variou de acordo com a genética dos animais.

$\mathrm{O}$ fato de neste estudo não ter ocorrido variação $(\mathrm{P}>0,05)$ no ganho de peso médio diário dos animais entre as genéticas pode ter contribuído para que não ocorresse interação entre planos de nutrição e as genéticas.

Não se observou efeito $(\mathrm{P}>0,05)$ das sequências de lisina digestível sobre o consumo de ração médio diário (CRD) dos animais, que também não variou $(\mathrm{P}>0,05)$ entre as linhagens genéticas. Da mesma forma, ao avaliarem sequências de lisina digestível, Gomes et al. 2000 (para suínos dos 30 aos $100 \mathrm{~kg}$ ), e Kill et al. 2003 (para suínos dos 65 aos $105 \mathrm{~kg}$ ) não verificaram variação na ingestão voluntária de ração dos animais, em função dos níveis de lisina digestível dos planos de nutrição.

De forma coerente com esses resultados, Owen et al. (1994) e Hahn et al.(1995), em estudos conduzidos com suínos na fase de crescimento e terminação; e Fontes et al. (2000) e Arouca et al. (2004; 2007), em 
trabalhos com suínos em terminação, também não constataram influência dos níveis de lisina sobre o consumo voluntário de ração dos animais. De acordo

com

Kerr et al. (2003), suínos toleram considerável excesso de aminoácidos na ração, entre eles lisina, sem variação na ingestão voluntária de alimentos.

Como não houve variação no consumo de ração médio diário dos animais das linhagens avaliadas, fica evidenciado que a capacidade de consumo não foi uma variável de diferenciação das duas linhagens. Em estudos para avaliação de níveis de lisina para suínos machos castrados de dois grupos genéticos (comum $\mathrm{x}$ melhorado) na fase de terminação, Moreira et al. (2002) não encontraram resposta diferenciada do consumo de ração médio diário aos níveis de lisina da ração, entre os animais das diferentes linhagens genéticas.

Os tratamentos influenciaram $(\mathrm{P}<0,01)$ o consumo de lisina médio diário (CLD), que aumentou à medida que se elevou as concentrações de lisina. Este resultado está consistente com os obtidos por Gomes et al. (2000) e Kill et al. (2003), que também encontraram relação direta entre o consumo diário de lisina com as suas concentrações nas sequências de lisina digestível utilizadas.

$\mathrm{O}$ fato de neste estudo o consumo de ração médio diário dos animais não ter variado, justifica a relação direta ocorrida entre o consumo de lisina digestível e a concentração desse aminoácido nos planos nutricionais.

Não houve diferença $(\mathrm{P}>0,05)$ no consumo de lisina médio diário dos animais das diferentes linhagens, o que está coerente com o fato de o consumo de ração médio diário não ter variado entre esses grupos de animais.
A conversão alimentar (CA) dos animais não sofreu influência $(\mathrm{P}>0,05)$ das sequências de lisina digestível. De forma consistente com esses dados, Gomes et al. (2000) também não verificaram influencia dos planos nutricionais, constituídos de diferentes níveis de lisina, sobre a eficiência de utilização do alimento para ganho de peso de suínos machos castrados dos 30 aos $100 \mathrm{~kg}$.

Em contrapartida, Kill et al. (2003), quando estudaram sequências de lisina digestível sobre o desempenho de suínos dos 65 aos $105 \mathrm{~kg}$, relataram efeito sobre a conversão alimentar. Da mesma forma, Owen et al. (1994), ao avaliarem níveis de lisina para suínos, dos 22 aos $109 \mathrm{~kg}$, verificaram efeito significativo dos tratamentos sobre a conversão alimentar dos animais. Variação na conversão alimentar dos suínos em terminação em função dos níveis de lisina da ração também foi observada por Fontes et al. (2000), Oliveira et al. (2003b) e Arouca et al. (2007).

Como a linhagem dos suínos em relação à capacidade de crescimento pode alterar a resposta da conversão alimentar dos animais ao nível de lisina da ração, conforme confirmado pelos resultados obtidos por Moreira et al. (2002), a ausência de efeito $(\mathrm{P}>0,05)$ sobre a conversão alimentar dos animais das diferentes genéticas avaliadas neste estudo justifica em parte os resultados obtidos.

Com relação às características de carcaça não houve efeito $(\mathrm{P}>0,05)$ das sequências de lisina digestível sobre a espessura de toucinho (ET) dos animais. Os dados da espessura de toucinho obtidos neste estudo estão consistentes com os de Arouca et al. (2004 e 2007) e com os de Moreira et al. (2002) que não verificaram efeito dos níveis de lisina sobre a espessura de toucinho dos 
Rev. Bras. Saúde Prod. Anim., Salvador, v.13, n.2, p.480-490 abr./jun., 2012 http://www.rbspa.ufba.br ISSN 15199940

suínos em terminação. No entanto, Kill et al. (2003), ao avaliarem sequências de níveis de lisina para suínos dos 65 aos $105 \mathrm{~kg}$ relataram variação significativa nos valores da espessura de toucinho da carcaça dos animais. Redução da espessura de toucinho da carcaça dos suínos em terminação, em razão do aumento da concentração da lisina na ração também foi observada por Owen et al. (1994) e Hahn et al. (1995).

Em estudo conduzido com suínos em terminação, Fontes et al. (2000) verificaram redução linear tanto na porcentagem quanto na taxa de deposição de gordura na carcaça, à medida que se elevou a concentração de lisina da ração.

Como o efeito dos níveis lisina da dieta sobre a espessura de toucinho é dependente do gasto de energia com a deposição de proteína (HAHN et al., 1995), o fato de o plano nutricional neste estudo não ter influenciado $(\mathrm{P}>0,05)$ a quantidade de carne na carcaça (QC) dos animais, justifica os resultados da espessura de toucinho obtidos.

Não foi verificada diferença $(\mathrm{P}>0,05)$ nos valores da espessura de toucinho e quantidade de carne na carcaça entre os animais das linhagens estudadas. Esses resultados estão de acordo com os dados de desempenho, nos quais não foi constatada diferença de resposta de ganho de peso médio diário e de conversão alimentar aos níveis de lisina digestível das rações. De acordo com Abreu et al. (2007a), suínos com maior capacidade de deposição de tecido magro têm maior exigência de lisina em relação aos de menor potencial de deposição.

A sequência de lisina digestível S1 $(0,80$; 0,70 e $0,60 \%$ atende as exigências nutricionais dos suínos das duas linhagens.

\section{REFERÊNCIAS}

ABREU, M.L.T.; DONZELE, J.L; OLIVEIRA, R.F.M.; OLIVEIRA, A.L.S.; SANTOS, F.A.; PEREIRA, A.A. Níveis de lisina digestível em rações utilizandose o conceito de proteína ideal para suínos machos castrados de alto potencial genético para deposição de carne magra dos 60 aos 95kg. Revista Brasileira de Zootecnia, v.36, n.1, p.54-61, 2007a.

ABREU, M.L.T.; DONZELE, J.L; OLIVEIRA, R.F.M.; OLIVEIRA, A.L.S.; SANTOS, F.A.; HAESE, D.; PEREIRA, A.A. Níveis de lisina digestível em rações utilizando-se o conceito de proteína ideal para suínos machos castrados de alto potencial genético dos 30 aos $60 \mathrm{~kg}$.

Revista Brasileira de Zootecnia, v.36, n.1, p.62-67, 2007b.

AROUCA， C.L.C.; FONTES， D.O.; BAIÃO, N.C.; SILVA, M.A.; SILVA, F.C.O. Níveis de lisina para suínos machos castrados selecionados geneticamente para deposição de carne magra na carcaça dos 95 aos $122 \mathrm{~kg}$, Ciência Agrotécnica, v.31, n.2, p.531539, 2007

AROUCA, C.L.C.; FONTES, D.O.; FERREIRA, W.M.; SILVA, M.A.; PEREIRA, F.A. Exigência de lisina com base no conceito de proteína ideal, para suínos machos castrados, de 95 a $122 \mathrm{~kg}$, selecionados para deposição de carne magra. Arquivo Brasileiro de Medicina Veterinária e Zootecnia, v.56, n.6, p.773-781, 2004.

FONTES, D.O.; DONZELE, J.L.; FERREIRA, A.S. Níveis de lisina para leitoas selecionadas para deposição de carne magra, dos 60 aos $95 \mathrm{~kg}$. Revista Brasileira de Zootecnia, v.29, p.784793, 2000. 
Rev. Bras. Saúde Prod. Anim., Salvador, v.13, n.2, p.480-490 abr./jun., 2012 http://www.rbspa.ufba.br ISSN 15199940

GASPAROTTO, L.F.; MOREIRA, I.; FURLAN, C.A.; MARTINS, E.N.; JÚNIOR, M.M. Exigência de lisina, com base no conceito de proteína ideal, para suínos machos castrados de dois grupos genéticos, na fase de crescimento.

Revista Brasileira de Zootecnia, Viçosa, v.30, n.6, p.1742-1749, 2001.

GOMES, F.E.; FIALHO, E.T.; LIMA, J.A.F.; OLIVEIRA, A.I.G.; BERTERCHINI, A.G.; GONÇALVES, T.M. Planos de nutrição baseados nos níveis de lisina para suínos de diferentes genótipos abatidos aos 80 e $100 \mathrm{~kg}$ de peso vivo. Ciência Agrotécnica. v.24, n.24, p.479-489, 2000.

HAHN, J.D.; BIEHL, R.R.; BAKER, D.H. Ideal digestible lysine for earlyfinishing and late-finishing swine.

Journal of Animal Science, v.73, p.773784, 1995.

KERR, B.J.; YEN, J.T.; NIENABER, J.A.; EASTER, R.A. Influence of dietary protein level, amino acid supplementation and environmental temperature on performance, body composition, organ weights and total heat production of growing pigs. Journal of animal Science, v.81, p.1998-2007, 2003.

KILL, J.L.; DONZELE, J.L.; OLIVEIRA. R.F.M.; FERREIRA, A.S.; LOPES, D.C.; SILVA, F.C.O.; SILVA, M.V.G.B. Planos de nutrição para leitoas com alto potencial genético para deposição de carne magra dos 65 aos $105 \mathrm{~kg}$. Revista Brasileira de Zootecnia, v.32, n.6, p.1330-1338, 2003.

LE FLOC, H. N.; MELCHIOR, D.; OBLED, C. Modifications of protein and amino acid metabolism during inflammation and immune system activation. Livestock Production Science, v.87, p.37-45, 2004.
LE FLOC'H, N.; MELCHIOR, D.; SÈVE, B. Dietary tryptophan helps to preserve tryptophan homeostasis in pigs suffering from lung inflammation. Journal of Animal Science, v.86, p.3473-3479, 2008.

MOREIRA, I.; GASPAROTTO, L.F.; FURLAN, A.C; PATRÍCIO, V.M.I.; OLIVEIRA, G.C. Exigência de lisina para suínos machos castrados de dois grupos genéticos de suínos na fase de terminação, com base no conceito de proteína ideal. Revista Brasileira de Zootecnia, v.31, n.1, p.96-103, 2002.

OLIVEIRA, A.L.S.; DONZELE, J.L.; OLIVEIRA, R.F.M.; LOPES, D.C.; MOITA, A.M.M.; SILVA, F.C.O.; FREITAS, L.S. Lisina em rações para suínos machos castrados selecionados para deposição de carne magra na carcaça dos 95 aos 110kg. Revista Brasileira de Zootecnia, v.32, n.2, p.337-343, 2003 a.

OLIVEIRA, A.L.S.; DONZELE, J.L.; OLIVEIRA, R.F.M.; FERREIRA, A.S.; GENEROSO, R.A.R. Lisina em rações para suínos machos castrados selecionados para deposição de carne magra na carcaça dos 110 aos $125 \mathrm{~kg}$. Revista Brasileira de Zootecnia, v.32, n.1, p.150-155, 2003 b.

OWEN, K.Q.; KNABE, D.A.; BURGOON, K.G.; GREGG, E.J. Selfselection of diets and lysine requirements of growing-finishing swine. Journal of Animal Science, v.72, p.554-564, 1994.

ROSTAGNO, H.S., ALBINO, L.F.T., DONZELE, J.L.; GOMES, P.C.; OLIVEIRA, R.F.; LOPES, D.C.; FERREIRA, A.S.; BARRETO, S.L.T. Composição de alimentos e exigências nutricionais de aves e suínos: tabelas brasileiras. Viçosa, MG:Universidade Federal de Viçosa, 2005. 186p. 
Rev. Bras. Saúde Prod. Anim., Salvador, v.13, n.2, p.480-490 abr./jun., 2012 http://www.rbspa.ufba.br ISSN 15199940

TREVISI, P.; MELCHIOR, D.; MAZZONI, M.; CASINI, L.; FILIPPI, S.; MINIERI, L.; LALATTACOSTERBOSA, G.; BOSI, P. A tryptophan-enriched diet improves feed intake and growth performance of susceptible weanling pigs orally challenged with Escherichia coli K88. Journal of Animal Science, v.87, p. 148-156, 2009.
YEN, H.T.; COLE, D.J.A.; LEWIS, D. Aminoacid requirements of growing pigs. 7. The response of pigs from 25 to $55 \mathrm{~kg}$ live weight to dietary ideal protein. Animal Production, v.43; p.141-154, 1986.

Data de recebimento: 29/06/2011

Data de aprovação: 19/04/2012 